\title{
The whole life cycle model of China's PPP water project: based on IDEF0 approach
}

\author{
Jiawei $\operatorname{Tian}^{1}$ and Chuan Chen ${ }^{1 *}$ \\ ${ }^{1}$ Business School, Sichuan University, Chengdu, Sichuan, 610065, People's Republic of China
}

\begin{abstract}
As a country with a large population and rapid development, the shortage of water resources is a serious challenge facing China. To meet the needs of domestic and industrial water, since the 1990s, China has begun to try to adopt the PPP delivery model in water projects. Compared with the traditional delivery mode, the PPP method includes the characteristics of high investment, many participants and long payback period. In order to better understand PPP, it is very important and meaningful to model the whole process of PPP project. Through literature review and case study, this paper established a whole life cycle model of China's PPP water project, which is helpful to better analyze and manage the various processes in the PPP water projects, so as to enhance the operational quality of PPP water projects.
\end{abstract}

\section{Introduction}

During the past few decades, the financial capacity of the Chinese government has been difficult to meet the needs of water supply infrastructure construction. In order to better utilize the advantages of the private sector in knowledge, skills, and resources, PPP has attracted more and more attention. Generally speaking, PPP can be defined as a cooperative arrangement between the public sector and private participants [4]. Since China began to implement the PPP arrangement in water projects in 1997 [1], many studies have been conducted on the application of PPP in China's water projects. Some studies use case analysis to study the development, advantages and problems needing attention of PPP in China's water projects $[7,10]$, Some studies have identified, evaluated and allocated the risk factors involved in PPP projects $[2,8,9]$, Some efforts focus on how to evaluate the performance of PPP water projects [6].

However, since the application of PPP arrangement in China is still in its infancy, there is no research to establish a model describing the whole life cycle of China's PPP water projects. Compared with the traditional delivery model, PPP has the characteristics of high investment, many participants and long payback period, so it is necessary and meaningful to analyze PPP by establishing a generic model. Based on the literature review and case study, this paper uses the IDEF0 method to propose a generic model of the whole life cycle of China's PPP water projects from the perspective of project managers, which can help better understand and analyze PPP water projects, and is also helpful to enhance the operational quality of PPP water projects.

\section{Materials and Methods}

At first, this paper used a literature review to review the relevant research on the application of IDEF0 in the PPP field, and identified the various processes of the PPP water project and the factors included in these processes, so as to build out an initial model. Then case study was conducted to modify and improve the initial model, a generic model of China's PPP water projects was finally established.

\subsection{Literature review}

In order to build the initial model, the existing process model and literature related to PPP water projects were reviewed. The China's Build -Operate- Transfer Generic Process Model (CBGPM) established by Chan [3] was used as a reference for model construction. Extensive literature related to PPP water projects was reviewed to understand the detailed process information of China's PPP water projects. By combining the obtained information with the reference model, an initial model was constructed.

\subsection{Case study}

A case study was then adopted to test and modify the initial model. The Chengdu No. 6 Water Plant B was chosen for the case study because it is the first and only PPP water project successfully transferred in China, and there has been a lot of research about this project. The detailed information of the project is shown in Table 1. Through case study, a generic model of the whole life cycle of China's PPP water project has been constructed.

\footnotetext{
* Corresponding author's e-mail: chenchuan@scu.edu.cn
} 
Table 1. Detailed information of The Chengdu No. 6 Water Plant.

\begin{tabular}{ll}
\hline PPP model & Build-operate-transfer (BOT) \\
& \\
\hline Sponsors & Veolia (60\% equity) \\
& Marubeni (60\% equity) \\
Lenders & ADB \\
& EIB \\
Project contents & $\begin{array}{l}\text { A water plant, water intake facilities, a discharge pipeline, and an aqueduct } \\
\text { that connects a waterworks to a city water supply network }\end{array}$ \\
Capacity of the water plant & 400 \\
$\left(1,000 \mathrm{~m}^{3} /\right.$ day) & 18 \\
Contract term (years) & 106.5 \\
Total investment (US $\$ \mathrm{~m})$ & 1999 \\
Financial closure year &
\end{tabular}

\subsection{IDEFO}

The basic concept of IDEF0 is developed on the basis of the structural analysis method proposed in the 1970s. IDEF0 consists of input, output, mechanism and control (ICOM). The structure of the model is shown in Figure 1 [5]. IDEF0 provides a comprehensive description of the

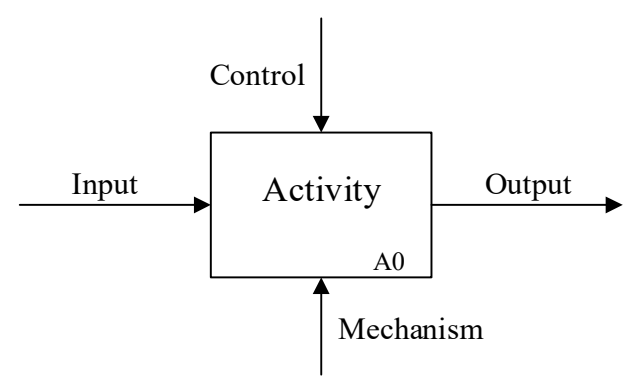

Figure 1. The structure of IDEF0 model

\section{Results \& Discussion}

Although there have been previous studies on the application of IDEF0 to PPP process model construction, such as Chen and Bao, there is still no research on the description and analysis of the process of PPP water projects in China. The purpose of this section is to describe the whole process of a PPP water project and to arrive at a generic model of the PPP water project in China.

\subsection{Description of PPP water project process}

This IDEF0 model is established based on the perspective of the project manager. It is a general description of the entire life cycle of a PPP water project.

In Figure 2, the A-0 layer of the model is shown, which system by using a top-down anatomical approach in system analysis, which can simultaneously express system activities (indicated by boxes) and data flows (indicated by arrows) and the connections between them, thereby comprehensively describing the system. In this paper, IDEF0 is used to describe the various processes of the PPP water project and the information related to these processes.

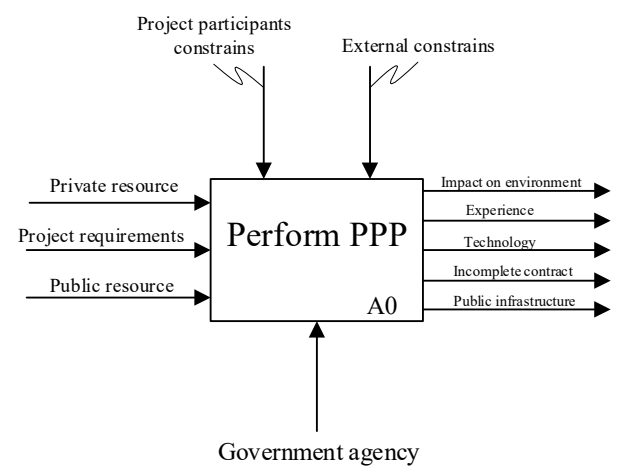

Figure 2. A-0 layer of PPP water project

is the most general description of the whole process of PPP water project in China. The input factors of this process are private resource, project requirements and public resources, while the output factors are public infrastructure, incomplete contract, experience, technology, and the impact on the environment. The whole life cycle of the PPP water project is restricted by two factors, namely external constraints (such as laws, weather, etc.) and project participant constraints (participants' experience, human resources, etc.). The mechanism of this project is the government agency.

The A-0 layer is then decomposed into the A0 layer, which contains the same information as the A-0 layer. In the A0 layer, there are six activities, which will be discussed in the following section. The structure of the whole PPP water project is displayed in Table 2.

Table 2. Structure of China's PPP water project process.

\begin{tabular}{ll}
\hline A0: Perform PPP & A4: Operate infrastructure \\
A1: Prepare Project & A41: Manage operations \\
A11: Make project proposal & A42: Monitor infrastructure conditions\& system \\
A12: Make pre-feasibility study & A43: Evaluate condition\& detect problems \\
A13: Get approval & A44: Develop solutions \\
\hline
\end{tabular}




\begin{tabular}{ll}
\hline A2: Implement Bidding & A5: Transfer infrastructure \\
A21: Prepare pre-qualification\& Bidding & A51: Prepare transfer \\
A22: Identify pre-qualified parties & A52: Assess and test assets \\
A23: Prepare ITB\& submit proposal & A53: Perform assets transfer \\
A24: Review proposals\& select bidders & A54: Evaluate PPP performance \\
A25: Negotiate and select the last sponsor & A6: Manage Infrastructure \\
A26: Execute contracts & A61: Establish project company \\
A3: Construct Infrastructure & A62: Develop work scope\& needs \\
A31: Design infrastructure & A63: Control Infrastructure \\
A32: Construct infrastructure & A64: Acquire services\& resource \\
A33: Commission\& accept infrastructure & \\
\hline
\end{tabular}

\subsection{Model}

In this section, the whole life cycle model of China's PPP water project established by the IDEF0 method is shown. The six sub-processes of the project process and their corresponding inputs, outputs, controls and mechanisms are identified. All mentioned above are shown in Figure 3.

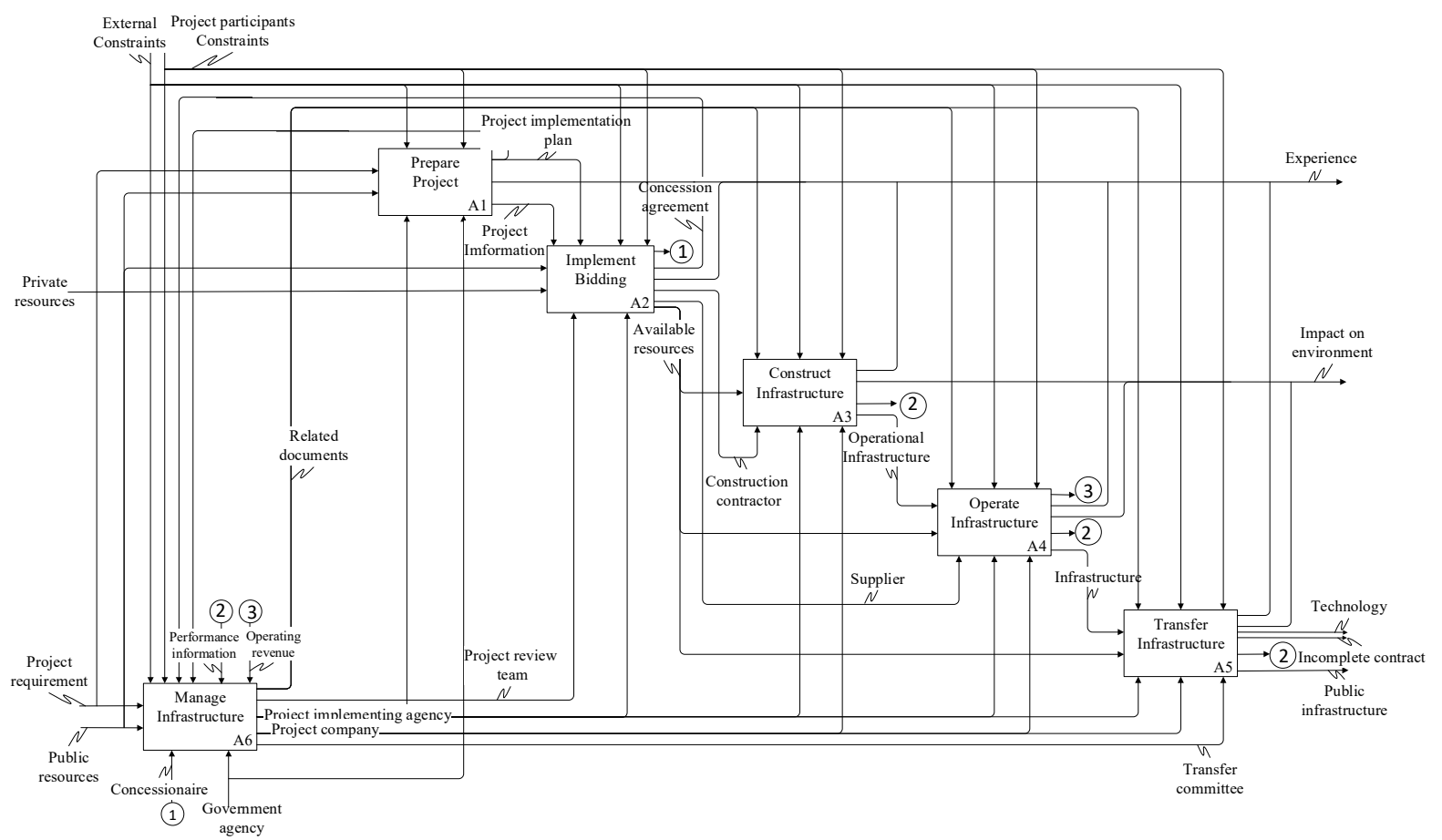

Figure 3. A0 layer of the PPP water project (2nd layer)

\subsection{Explanation of 6 sub-processes}

At A0 layer, the whole life cycle of a PPP water project is broken down into 6 sub-processes. This section describes the 6 sub-processes in detail.

\subsubsection{A1: Prepare project.}

Before deciding to start a PPP project, it is necessary to conduct a feasibility study on the project to ensure that the project can achieve value for money, and prepare the corresponding project implementation plan as the basis for the subsequent process.

\subsubsection{A2: Implement bidding.}

In accordance with relevant laws and regulations, select partners from bidding social capital and sign relevant agreements. Sometimes it also needs to include the formation of a project company.

\subsubsection{A3: Construct infrastructure.}

Social capital authorizes construction contractor and organizes relevant parties to complete the construction of water supply infrastructure under the supervision of government departments.

\subsubsection{A4: Operate infrastructure.}

The project company shall operate and maintain the project facilities as required by the agreement. To ensure that the operation of the project can achieve the desired objectives. 


\subsubsection{A5: Transfer infrastructure.}

After the end of the project operation period and the expiration of the franchise period, the project company shall transfer the project's operating rights (or ownership and operating rights at the same time) to the government, and the government will evaluate the performance of the project.

\subsubsection{A6: Manage infrastructure.}

Monitor and manage all aspects of the project in the whole life cycle of the project, so as to ensure the smooth progress of PPP project.

\section{Conclusions}

In this paper, from the perspective of project managers, a generic model describing the whole life cycle of China's PPP water projects has been established through IDEF0 method. In this model, the whole process of PPP water projects was decomposed into 6 sub-processes and analyzed. This model would help PPP project managers to better understand and analyze the various processes in PPP water projects, thereby improving management efficiency and quality. It is also helpful for researchers to carry out relevant researches on PPP water projects in China.

\section{References}

1. Bao, F., et al. (2019) Dynamic framework transfer model for public-private partnerships. Engineering, Construction and Architectural Management., 26: 1218-1239.

2. Chan, A. P. C., et al. (2015) Cross-Sectional Analysis of Critical Risk Factors for PPP Water Projects in China. Journal of Infrastructure Systems., 21.

3. Chan, W. T., et al. (2005) Interface management for China's build-operate-transfer projects. Journal of Construction Engineering and Management., 131: 645-655.

4. Hodge, G. A. and C. Greve. (2007) Public-private partnerships: An international performance review. Public Administration Review., 67: 545-558.

5. Khoo, L. P., et al. (1999) An IDEF0 model-based intelligent fault diagnosis system for manufacturing systems. International Journal of Production Research., 37: 35-48.

6. Li, H. M., et al. (2020) Public satisfaction evaluation of urban water environment treatment public-private partnership project A case study from China. International Journal of Building Pathology and Adaptation.

7. Qian, N., et al. (2020) Public-private partnerships in the water sector in China: a comparative analysis. International Journal of Water Resources Development., 36: 631-650.

8. Shrestha, A., et al. (2017) Risks in PPP Water Projects in China: Perspective of Local Governments. Journal of Construction Engineering and Management., 143.

9. Shrestha, A., et al. (2018) Risk Allocation Inefficiencies in Chinese PPP Water Projects. Journal of Construction Engineering and Management., 144.

10. Zhong, L. J., et al. (2008) Public-private partnerships in China's urban water sector. Environmental Management., 41: 863-877. 